\title{
Genetic variation in the Critically Endangered velvet worm Opisthopatus roseus (Onychophora: Peripatopsidae)
}

\author{
Savel R. Daniels* \\ Department of Botany and Zoology, University of Stellenbosch, \\ Private Bag X1, Matieland, 7602 South Africa \\ Received 7 February 2011. Accepted 30 March 2011
}

In the present study the genetic variation of the Critically Endangered velvet worm species Opisthopatus roseus is examined. This species is endemic to the Ngele mistbelt forest in the KwaZulu-Natal province of South Africa. In recent years the forest has been severely impacted by anthropogenic activities such as logging of indigenous trees, construction of a national highway, commercial timber plantations and introduction of alien plant species, resulting in habitat fragmentation and potential range contraction for the species. A total of 35 specimens were collected from five sample sites (logs) in the Ngele Forest and sequenced for a partial fragment of the cytochrome $c$ oxidase subunit one (COI) locus. In addition, the sex ratio at each sample sites was determined. A highly skewed sex ratio was detected within sites and only three males were present among the 350 . roseus specimens. The results reveal the presence of 11 haplotypes and moderate genetic differentiation between the five sampled sites. In addition, it is evident that samples from the same log represented a mixture of haplotypes and did not comprise a single maternal haplotype. The results further suggest that gene flow between individuals occurs in the interior of the forest. Conservation implications of the present study are briefly discussed.

Key words: Opisthopatus roseus, Critically Endangered, invertebrate conservation, genetic variation, haplotypes, saproxylic habitats.

\section{INTRODUCTION}

Highly sedentary organisms, characterized by microhabitat specificity involving saproxylic environments (decaying wood logs and leaf litter), generally exhibit low dispersal capabilities and may demonstrate marked phylogeographic structure over small spatial scales (Garrick et al. 2008). In South Africa, limited attention has been devoted to the population genetic structure and conservation of taxa confined to these habitats. The lack of genetic studies on such taxa is hampering the effective conservation of these species and their respective habitat. Velvet worms (Onychophora)

*E-mail: srd@sun.ac.za are a faunal group typically associated with saproxylic habitats within forest and fynbos (Mediterranean-type shrubby vegetation characterized by high diversity and endemism) ecosystems. In South Africa two velvet worm genera (Peripatopsis Pocock, 1894 and Opisthopatus Purcell, 1899) are present, which contain nine and three described species, respectively. Four of the described species, representing $\sim 36 \%$ of the country's fauna are currently IUCN Red-listed (Hamer et al. 1997; IUCN Red List 2011). These include three Peripatopsis species, namely P. alba Lawrence, 1931; P. clavigera Purcell, 1899 and P. leonina Purcell, 1899. The former two species are listed as Vulnerable, while the latter species is Critically Endangered (IUCN Red List 2011) and might have become extinct since it has not been recollected for a 100 years despite exhaustive attempts (S. Daniels pers. obs.). In addition, a single Opisthopatus species, O. roseus Lawrence, 1947, is currently listed as Critically Endangered, while the recently described species O. herbertorum Ruhberg \& Hamer, 2005 will be IUCN Red-listed shortly (Hamer et al. 1997; Ruhberg \& Hamer 2005; S. Daniels pers. obs.; IUCN Red List 2011).

Recent published systematic research on the genus Peripatopsis using gross morphology, scanning electron microscopy (SEM) and DNA sequence data (12S rRNA, COI and 18S rDNA) indicate that three of the species (P. balfouri Sedgwick, 1885, P. capensis Grube, 1866 and P. moseleyi WoodMason, 1879), previously characterized by wide geographic distributions, comprise several novel, undescribed lineages (Daniels et al. 2009; Daniels \& Ruhberg 2010). Furthermore, the latter findings suggest higher levels of endemism in the faunal group, signifying the need for a conservation assessment of these novel species. Similarly, DNA sequence data for the widely distributed velvet worm species Opisthopatus cinctipes Purcell, 1899 suggest that several novel cryptic lineages are 
nested within this widespread species with most lineages possessing narrow distribution ranges (S. Daniels, unpubl.). Consequently, a study was initiated to examine the genetic variation of the Critically Endangered velvet worm species $O$. roseus to explore its population genetic structure, which might be helpful for developing a conservation management plan for the species and its habitat.

Opisthopatus roseus is endemic to Ngele Forest in the southern region of the KwaZulu-Natal province, South Africa (Hamer et al. 1997). The forest encompasses $6.93 \mathrm{~km}^{2}$ and is a naturally patchy mistbelt forest that ranges in altitude between 1250 and $1550 \mathrm{~m}$ above sea level. Ngele Forest also harbours populations of the Endangered mistbelt chirping frog (Anhydrophryne ngongoniensis, Bishop \& Passmore, 1993) and the Critically Endangered Cape parrot (Poicephalus robustus Gmelin, 1788), making the conservation of the forest a priority. Historically, large numbers of indigenous trees were felled since 1890 following the establishment of a sawmill, resulting in further forest fragmentation. More recently, the forest has been bisected by the construction of a national highway, the N2. The areas adjacent to the forest have been transformed by extensive commercial pine (Pinus) and blue gum (Eucalyptus) timber plantations, as well as by the encroachment of alien plant species. The forest is further impacted by the collection of wood for fuel, the stripping of bark, which is used for medicinal purposes, and the use of the forest for cattle grazing by the local communities (S. Daniels pers. obs.). The habitat quality within the forest is thought to have decreased due to these anthropogenic impacts and has further fragmented the indigenous forest. Collectively, these factors have likely impacted the distribution of the species, since the species has only been found sporadically (see comments in Hamer et al. 1997). However, the latter result may simply reflect sampling effort or the difficulty in locating $O$. roseus specimens. In the present study, the genetic variation within $O$. roseus is examined. These results represent the first conservation genetic study undertaken on a Critically Endangered velvet worm species.

\section{MATERIALS \& METHODS}

Sample collection, DNA extraction, amplification and sequencing

A total of 35 specimens of Opisthopatus roseus were collected during July 2010 from five sample sites (logs) in the Ngele Forest, KwaZulu-Natal, South Africa (Fig. 1; Table 1). Three of the sample sites $(1,2$ and 3$)$ were on the southern side of the forest, while the two remaining sample sites ( 4 and 5) were on the northern side of the forest (Fig. 1). Samples were preserved directly in absolute ethanol and a GPS record was taken at each sampled log (Table 1). The sex of specimens at each sample site was determined by examining the genital areas (Hamer et al. 1997). A small tissue sample was then dissected from each specimen and the DNA extracted using the DNeasy Tissue Kit (Qiagen, Germany) using the manufacturer's protocol. The extracted DNA was diluted and the cytochrome c oxidase subunit one (COI) locus was amplified using standard PCR conditions. The primer pairs LCOI 1490 and HCOI 2198 were used to amplify the COI locus (Folmer et al. 1998). This locus has been used widely to examine population genetic structure among invertebrates, including velvet worms (Trewick 2000; Daniels et al. 2009; Daniels \& Ruhberg 2010). Detailed conditions for the PCR and DNA sequencing used in the present study are outlined in Daniels et al. (2009) and Daniels \& Ruhberg (2010). Samples collected during the present study will be deposited in the Iziko South African Museum (SAM) at the termination of the present study on the systematic revision of the genus Opisthopatus.

\section{Phylogenetic analyses}

Aligned forward and reverse sequences were checked for base ambiguity in Sequence Navigator (Applied Biosystems) and a consensus sequence was created for each sample. The COI sequences were aligned in CLUSTAL X (Thompson et al. 1997). Phylogenetic data analyses were executed in PAUP* 4 version beta 10 (Swofford 2002) using minimum evolution (ME). Phylogenetic confidence in the nodes recovered was estimated by bootstrapping (Felsenstein 1985), analysing 10000 bootstrap pseudo-replicates for ME. For the Bayesian analysis, the best-fit substitution model was determined using MODELTEST version 3.06 (Posada \& Crandall 1998), and selected using the Akaike Information Criterion (AIC) (Akaike 1973). This reduces the number of unnecessary parameters that contribute little to describing the data by penalizing more complex models (Burnham \& Anderson 2002; Nylander et al. 2004; Posada \& Buckley 2004). Bayesian inferences were used to investigate optimal tree space using the program MrBayes 3.0b4 (Ronquist \& Huelsenbeck 2003). 


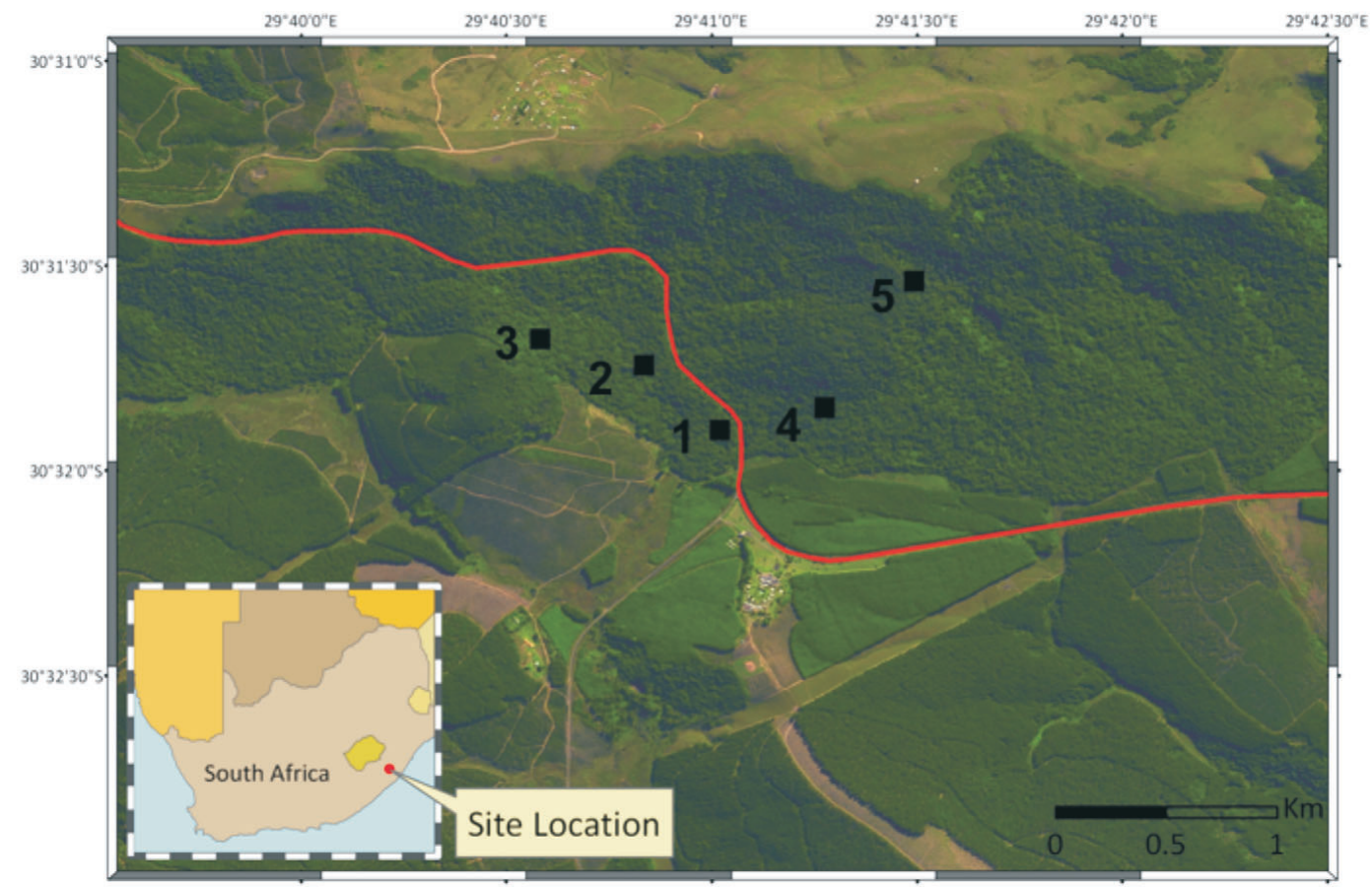

Fig. 1. Localities in the Ngele Forest, KwaZulu-Natal, South Africa, where specimens of Opisthopatus roseus were sampled. The line in the centre of the map denotes the N2 national highway that bisects the forest. Sites 1-5 correspond to the collection sites in Table 1.

For each analysis four Markov chains were run, with each chain started from a random tree, for five million generations. Sampling from the chain occurred every 5000th generation. A 50\% majority rule consensus tree was generated from the trees retained after the burn-in trees were discarded, with posterior probabilities $(\mathrm{p} P)$ for each node estimated by the frequency at which the node was recovered. Two Opisthopatus cinctipes samples from Rivendell farm (Eastern Cape Province, South Africa) and Graskop (Mpumalanga province, South Africa) were used to root the tree topology. Uncorrected (' $\mathrm{p}$ ') sequence distances were

Table 1. List of the five localities within Ngele Forest, KwaZulu-Natal, South Africa, where specimens of the Critically Endangered velvet worm species Opisthopatus roseus was collected. $n$ represents the number of specimens collected at each of the five sample sites.

\begin{tabular}{lrcc}
\hline Locality & $n$ & $\mathrm{~S}$ & $\mathrm{E}$ \\
\hline Site 1 & 8 & $30^{\circ} 31^{\prime} 901^{\prime \prime}$ & $29^{\circ} 41^{\prime} 020^{\prime \prime}$ \\
Site 2 & 10 & $30^{\circ} 31^{\prime} 743^{\prime \prime}$ & $29^{\circ} 40^{\prime} 836^{\prime \prime}$ \\
Site 3 & 7 & $30^{\circ} 31^{\prime} 679^{\prime \prime}$ & $29^{\circ} 40^{\prime} 582^{\prime \prime}$ \\
Site 4 & 7 & $30^{\circ} 31^{\prime} 847^{\prime \prime}$ & $29^{\circ} 41^{\prime} 276^{\prime \prime}$ \\
Site 5 & 3 & $30^{\circ} 31^{\prime} 538^{\prime \prime}$ & $29^{\circ} 41^{\prime} 494^{\prime \prime}$ \\
Total & 35 & & \\
\hline
\end{tabular}

calculated in PAUP*4 version beta 10 (Swofford 2002).

\section{Population level analyses}

A haplotype network was constructed using TCS software version 1.13 (Clement et al. 2000) with a $95 \%$ parsimony probability for the COI locus. An analysis of molecular variance (AMOVA) was performed on the data using ARLEQUIN version 3.0 (Excoffier et al. 2005) to calculate population differentiation over all sample sites $\left(\Phi_{\mathrm{ST}}\right)$.

\section{RESULTS \& DISCUSSION}

The sex ratio among the five sample sites was highly skewed towards females. At sites 1,2 and 3 a single male was present at each site with the remainder of the specimens comprising females only. At sites 4 and 5 only female specimens were present. The low frequency presence of males is difficult to explain, and may represent a sampling artefact; alternatively, males might have different demographic histories. This requires further investigation. A 622 base pair fragment of the COI locus was amplified for the 35 specimens collected. The COI sequences were converted to amino acids. No stop codons, or inserts and deletions 
were detected suggesting that the sequences are functional and does not represent pseudogenes. The substitution model selected for the COI locus using the AIC criteria was TVM+I ( $-1 \mathrm{nl}=1635.88$; $\mathrm{AIC}=3287.76)$. The base frequencies were $\mathrm{A}=$ $29.49 \%, \mathrm{C}=14.44 \%, \mathrm{G}=16.09 \%$ and $\mathrm{T}=39.98 \%$, while the rate matrix was $\mathrm{R}(\mathrm{a})[\mathrm{A}-\mathrm{C}]=4.04$, $\mathrm{R}(\mathrm{b})[\mathrm{A}-\mathrm{G}]=47.97, \mathrm{R}(\mathrm{c})[\mathrm{A}-\mathrm{T}]=19.54$, $\mathrm{R}(\mathrm{d})[\mathrm{C}-\mathrm{G}]=0.00, \mathrm{R}(\mathrm{e})[\mathrm{C}-\mathrm{T}]=47.97$ and $\mathrm{R}(\mathrm{f})[\mathrm{G}-\mathrm{T}]=1.00$ and the proportion of invariable sites was $(\mathrm{I})=0.66$. The COI locus was $\mathrm{A}$ and $\mathrm{T}$ rich. High $\mathrm{A}$ and $\mathrm{T}$ ratios have been reported for the COI locus in other velvet worm species studied to date (Trewick et al. 2000; Rockman et al. 2001; Daniels et al. 2009; Daniels \& Ruhberg 2010). The phylogenetic tree revealed the monophyly of the 35 O. roseus samples (100\% for ME and $1.00 \mathrm{pP}$ for Bayesian analyses). No distinct clades were evident on the tree topology and samples from both the northern and southern sections of the forest interdigitated on the tree (topology not shown). Haplotype one from site 5 was genetically distinct. Considering the low divergence between samples, tree-building methods (ME / Bayesian analyses) may not offer the optimal resolution for understanding the population genetic structure of a narrow endemic species, hence a network was constructed.

The TCS analyses of the 35 COI sequences retrieved 11 haplotypes (Fig. 2; Table 2). The 11 haplotypes have been deposited in GENBANK (accession numbers JF 742791-JF 742801). The results further suggest that high haplotype diversity is present within the species, considering the small area sampled within the Ngele Forest. One haplotype (h) sampled at site 5 (h 1) could not be connected with the remaining ten haplotypes with $95 \%$ confidence, corroborating the genetic distinctness of this sample. The number of haplotypes ranged from two at sites 1 and 5, to three at sites 2 and 3 to four at site 4 . Evident from the haplotype network analysis is that most

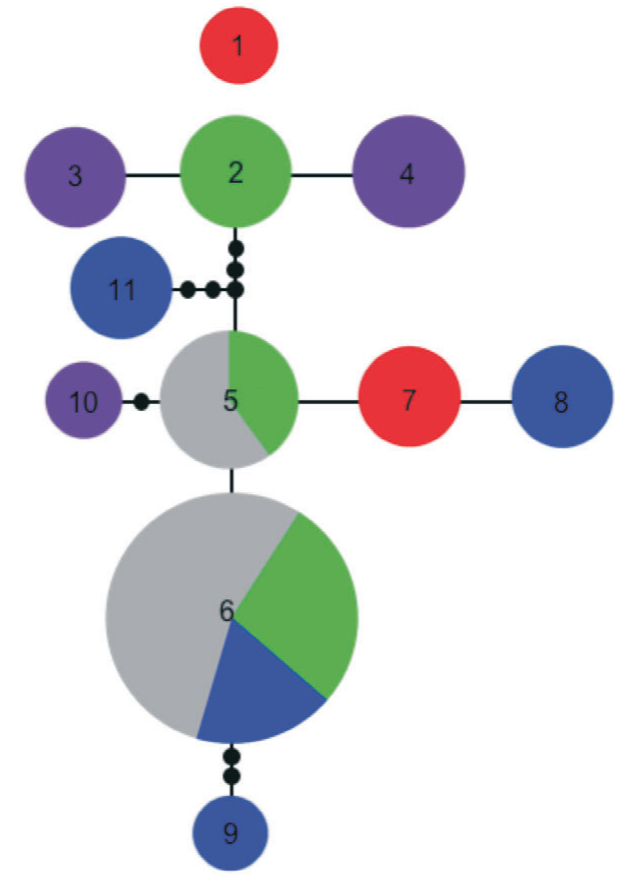

Fig. 2. A haplotype network produced using the TCS software for the eleven $\mathrm{CO} /$ haplotypes detected among the five sites sampled for Opisthopatus roseus. The size of each circle represents the frequency of the haplotype and the number inside each haplotype corresponds to the haplotype number in Table 2.

sampled sites comprise a mixture of haplotypes. For example, at site 1, two haplotypes (h 5 and $\mathrm{h} 6$ ) were present, and the identical haplotypes were present at site 2, while h 6 was present at site 4 . However, the latter two sample sites also contained unique haplotypes (Table 2). These results suggest that there is dispersal between sample sites (logs) and that samples from within a log do not comprise a single maternal lineage or reproductive unit. Haplotypes from the northern side of the forest, at site 4 were present at both sites 1 and 2 on the southern sample sites of the forest, indicating that velvets worms disperse across the road or

Table 2. Frequency of the eleven COI haplotypes at five sample localities of Opisthopatus roseus.

\begin{tabular}{|c|c|c|c|c|c|c|c|c|c|c|c|}
\hline \multirow[t]{2}{*}{ Locality } & \multicolumn{11}{|c|}{ Haplotypes } \\
\hline & 1 & 2 & 3 & 4 & 5 & 6 & 7 & 8 & 9 & 10 & 11 \\
\hline Site 1 & & & & & 2 & 6 & & & & & \\
\hline Site 2 & & 4 & & & 3 & 3 & & & & & \\
\hline Site 3 & & & 2 & 4 & & & & & & 1 & \\
\hline Site 4 & & & & & & 2 & & 2 & 1 & & 2 \\
\hline Site 5 & 1 & & & & & & 2 & & & & \\
\hline
\end{tabular}


alternatively suggest that the construction of the road was too recent to have impacted the population genetic structure of the species.

The AMOVA results over all sampled localities revealed that $34.40 \%\left(\Phi_{\mathrm{ST}}=0.3440\right.$, d.f. $=4, \mathrm{Va}=$ $78.68, P<0.001)$ of the variation occurred among sites, and $65.60 \%$ of the variation occurred within sites (d.f. $=30, \mathrm{Vb}=1.50, P<0.001$ ). It appears that specimens disperse from their natal ranges to form loose social aggregations where multiple reproductive females can co-inhabit the same log. These results suggest that sample sites (logs) comprise a large number of distinct haplotypes underscoring the importance of decaying environments to harbour genetically distinct individuals. Furthermore, these results indicate that there is dispersal between logs in the forest interior, but that dispersal becomes limited towards the periphery of the forest. However, considering the small area sampled, compared to the high haplotype diversity, these results would suggest that females exhibit limited dispersal (evident from the large number of private haplotypes) promoting genetic differentiation between sample sites. Similar observations have been made for Euperipatoides rowelli Reid, 1996 while studying the social behaviour of the species (Reinhard \& Rowell 2005), suggesting that female dispersal might be limited in general among conspecific velvet worms populations. Clearly observations into the social organization and behaviour of $O$. roseus would help to understand the population genetic structure of the species. However, such studies are currently lacking. The maximum uncorrected sequence divergence values for the COI locus were $2.89 \%$. The latter value compares favourably with those observed within populations for other velvet worm species. For example, Daniels et al. (2009) reported $<2 \%$ variation within sample sites for the described Peripatopsis velvet worm species. Notably, these species are distributed over a broader geographic range compared to O. roseus.

Microsatellite markers would offer a more sensitive method to infer the population genetic structure of the species. However, microsatellites are notoriously difficult to optimize in velvet worms (Sunnucks \& Wilson 1999), suggesting that the use of rapidly evolving mtDNA sequence data, although limited, currently offers the best insight into the population genetic structure among velvet worm species. Although nDNA sequence markers have been developed for selected Australian velvet worm species (Rockman et al. 2001; Sands et al.
2009), attempts of using these markers in Opisthopatus were unsuccessful (S. Daniels, unpubl.). The latter result may be attributed to the fact that the two South African genera are paraphyletic with the two Chilean genera and distantly related to the Australian Peripatopsidae (Daniels et al. 2009; Allwood et al. 2010). Divergence time estimations suggest that representatives of the South African and Australian velvet worm fauna have diverged $>100$ million years ago (Allwood et al. 2010), further underscoring the evolutionary antiquity of the continental faunas and explaining the lack of cross-amplification of the nDNA primer pairs.

In South Africa, wood is frequently removed from forest and fynbos to minimize the impact of fire on these ecosystems. According to the present findings, this practice should be restricted to the periphery of the forest in order to limit the impact on the habitat of the species without compromising current fire regime management. Indigenous trees in the forest, fallen after storms should be left to decay and not removed since they provide an essential habitat for the species. Both O. roseus and its habitat are legally protected and permits are required for sample collection. Over-collection is unlikely to represent a significant threat to the population size since velvet worms are notoriously difficult to collect. New timber plantations should be restricted to the forest periphery, and any future logging of indigenous forest should be stopped or conducted in a manner that allows for interconnectivity between forest patches. Opisthopatus roseus is absent from non-native decaying logs in the timber plantations adjacent to the indigenous forest (S. Daniels, pers. obs.), probably due to the limited humidity of the logs and the absence of natural vegetation cover that may aid its dispersal and which creates suitable microclimatic environments. Similar conservation strategies have been proposed for two Tasmanian velvet worm species (Tasmanipatus barretti Ruhberg et al. 1991 and T. anophthalmus Ruhberg et al. 1991) (Mesibov 1990). Continued surveys are recommended to monitor the populations of Critically Endangered O. roseus. Educational opportunities also exist to inform the public about the significant conservation value of the Ngele forest since it is a popular area for hiking. These results demonstrate the importance of conserving saproxylic environments in South Africa since these habitats are reservoirs of genetic diversity for velvet worm species. 
I wish to thank the University of Stellenbosch for logistical support and both the National Research Foundation (SABI initiative) and a NORAD SANBI grant for financial support to undertake the research. Nicholas Solomons and Francois van Zyl are thanked for assistance during fieldwork in KwaZulu-Natal, South Africa. Ezemvelo KwaZulu-Natal Wildlife is thanked for a collection permit (2133/2010) to conduct this study. Ilze Boonzaaier is thanked for designing the map. Michelle Hamer and Georg Mayer are thanked for constructive comments that helped to improve the quality of the publication. Hilke Ruhberg is thanked for determining the sex of specimens at each of the five sample localities.

\section{REFERENCES}

AKAIKE, H. 1973. Information theory as an extension of maximum likelihood principle. In: Second International Symposium on Information Theory, (eds) B.N. Petrov \& F. Csake, pp. 267-281. Akademiai Kaido, Budapest.

ALLWOOD, J., GLEESON, D., MAYER, G., DANIELS, S., BEGGS, J.R. \& BUCKLEY, T.R. 2010. Support for vicariant origin of the New Zealand Onychophora. Journal of Biogeography 37: 669-681.

BURNHAM, K.P. \& ANDERSON, D.R. 2002. Model Selection and Multi-model Inferences, a Practical Information-theoretic Approach, 2nd edn. Springer, New York.

CLEMENT, M.D., POSADA, D. \& CRANDALL, K.A. 2001. TCS. A computer program to estimate gene genealogies. Molecular Ecology 9: 1657-1660.

DANIELS, S.R. \& RUHBERG, H. 2010. Molecular and morphological variation in a South African velvet worm, Peripatopsis moseleyi (Onychophora, Peripatopsidae): evidence for cryptic speciation. Journal of Zoology, London 282: 171-179.

DANIELS, S.R., PICKER, M., COWLIN, R.M. \& HAMER, M. 2009. Unravelling evolutionary lineages among the South African velvet worms (Onychophora: Peripatopsis) provides evidence for widespread cryptic speciation. Biological Journal of the Linnean Society 97: 200-216.

EXCOFFIER, L., LAVAL, G. \& SCHNEIDER, S. 2005. Arlequin (version 3.0): an integrated software package for population genetics data analysis. Evolutionary Bioinformatics 1: 47-50.

FELSENSTEIN, J. 1985. Confidence limits on phylogenies: an approach using the bootstrap. Evolution 39: 783-791.

FOLMER, O., BLACK, M., HOEH, W., LUTZ, R. \& VREIJENHOEK, R. 1994. DNA primers for amplification of mitochondrial cytochrome c oxidase subunit I from diverse metazoan invertebrates. Molecular Marine Biology and Biotechnology 3: 294-299.

GARRICK, R.C., ROWELL, D.M., SIMMONS, C.S., HILLIS, D.M. \& SUNNUCKS, P. 2008. Fine-scale phylogeographic congruence despite demographic incongruence in two low-mobility saproxylic springtails. Evolution 62: 1103-1118.

IUCN 2011. IUCN Red List of Threatened Species. Version 2011.1. Online at: http://www.iucnredlist.org (downloaded 16 June 2011).

HAMER, M.L, SAMWAYS, M. \& RUHBERG, H. 1997. A review of the Onychophora of South Africa, with discussion of their conservation. Annals of the Natal Museum 38: 283-312.

MESIBOV, B. 1990. Velvet worms: a special case of invertebrate fauna conservation. Tasforests 2: 53-56.

NYLANDER, J.A.A.A., RONQUIST. F., HUELSENBECK, J.P \& NIEVES-ALDREY, J.L. 2004. Bayesian phylogenetic analysis of combined data. Systematic Biology 53: 47-67.

REINHARD, J. \& ROWELL, D.M. 2005. Social behaviour in an Australian velvet worm, Euperipatpides rowelli (Onychophora: Peripatopsidae). Journal of Zoology, London 267: 1-7.

ROCKMAN, M.V., ROWELL, D.M., TAIT, N.N. 2001. Phylogenetics of Planipapillus, lawn-headed Onychophora of the Australian Alps, based on nuclear and mitochondrial gene sequences. Molecular Phylogenetics and Evolution 21: 103-116.

RONQUIST, F. \& HUELSENBECK, J.P. 2003. MrBayes 3: Bayesian phylogenetic inference under mixed models. Bioinformatics 19: 1572-1574.

RUHBERG, H. \& HAMER, M.L. 2005. A new species of Opisthopatus Purcell, 1899 (Onychophora: Peripatopsidae) from KwaZulu-Natal, South Africa. Zootaxa 1039: 27-38.

SANDS, C., LANCASTER, M.L., AUSTIN, J.J. \& SUNNUCKS, P. 2009. Single copy nuclear DNA markers for the onychophoran Phallocephale tallagandensis. Conservation Genetics Resources 1: 17-19.

SUNNUCKS, P. \& WILSON, A.C.C. 1999. Microsatellite markers for the onychophoran Euperipatoides rowelli. Molecular Ecology 8: 899-900.

SWOFFORD, D.L. 2002. PAUP* Phylogenetic Analysis Using Parsimony (and other methods), Version 4.10. Illinois Natural History Survey, Champaign, Illinois.

POSADA, D. \& BUCKLEY, T.R. 2004. Model selection and model averaging in phylogenetics: advantages of the AIC and Bayesian approaches over likelihood ratio tests. Systematic Biology 53: 793-80.

POSADA, D. \& CRANDALL, K.A. 1998. MODELTEST: testing the model of DNA substitution. Bioinformatics 14: 817-818.

THOMPSON, J.D., GIBSON, T.J., PLEWNIAK, F., JEANMOUGIN, F. \& HIGGINS, D.G. 1997. The Clustal $X$ windows interface: flexible strategies for multiple sequence alignment aided by quality analysis tools. Nucleic Acid Research 24: 4876-4882.

TREWICK, S.A. 2000. Mitochondrial DNA sequences support allozyme evidence for cryptic radiation of New Zealand Peripatoides (Onychophora). Molecular Ecology 9: 269-281.

Responsible Editor: J.H. van Wyk 